Terbit online pada laman : http://teknosi.fti.unand.ac.id/

Jurnal Nasional Teknologi dan Sistem Informasi

ISSN (Print) 2460-3465 | ISSN (Online) 2476-8812 |

Artikel Penelitian

\title{
Sistem Penentuan Kualitas Hewan Qurban di Indonesia dengan Metode SAW
}

\author{
Renny Puspita Sari ${ }^{{ }^{*}}$, Ahmad Cahyono Adi ${ }^{a}$ \\ a Jurusan Sistem Informasi Universitas Tanjungpura, Jl. Prof.Dr.H. Hadari Nawawi, Kec. Pontianak Tenggara, Kota Pontianak, Kalimantan Barat 78124 Indonesia
}

\section{INFORMASI ARTIKEL}

Sejarah Artikel:

Diterima Redaksi: 16 Juni 2021

Revisi Akhir: 29 Agustus 2021

Diterbitkan Online: 31 Agustus 2021

\section{KATA KUNCI}

Kualitas Qurban

Simple Addictive Weighting

Sistem Pendukung Keputusan

\section{KORESPONDENSI}

E-mail: Rennysari@sisfo.untan.ac.id *

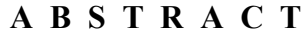

Setiap tahunnya, umat muslim didunia melaksanakan Ibadah Qurban termasuk di Indonesia. Berdasarkan data dari Direktorat Jenderal Peternakan dan Kesehatan Hewan jumlah hewan qurban di Indonesia pada tahun 2020 adalah sekitar 1.802.651 ekor dengan rincian hewan sapi, kerbau, kambing dan domba. Statistik hewan Qurban dari tahun ke tahun mengalami kenaikan. Hewan yang dapat di Qurbankan pada dasarnya memiliki syarat tertentu sesuai dengan fiqih Qurban. Oleh karena itu diperlukan pengecekkan terlebih dahulu apakah hewan tersebut layak jadi hewan Qurban. Tingginya angka Qurban di Indonesia mendorong lahirnya sebuah sistem pendukung keputusan yang dapat membantu dalam mengelompokkan hewan-hewan yang akan di Qurbankan di Indonesia. Sistem ini menerapkan metode perhitungan SAW (Simple Adictive Weighting) yang dapat mengklasifikasikan hewan Qurban yang di inputkan dengan kriteriakriteria tertentu. Hasilnya semua calon hewan Qurban akan secara otomatis diberi nilai yang memiliki arti tertentu apakah hewan tersebut untuk dapat jadi hewan Qurban. Dengan adanya sistem penentu hewan Qurban, diharapkan dapat mendorong peningkatan kualitas hewan Qurban yang ada di Indonesia.

\section{PENDAHULUAN}

Setiap tahunnya, umat muslim didunia melaksanakan Ibadah Qurban,tak terkecuali di Indonesia. Berdasarkan data dari Direktorat Jenderal Peternakan dan Kesehatan Hewan jumlah hewan qurban di Indonesia pada tahun 2020 adalah sekitar 1.802.651 ekor dengan rincian hewan sapi, kerbau, kambing dan domba [1]. Statistik hewan Qurban dari tahun ke tahun mengalami kenaikan. Qurban berasal dari bahasa Arab, "Qurban" (قربان), yang berarti dekat. Di dalam ajaran Islam, qurban disebut juga dengan al-udhhiyyah dan adh-dhahiyyah yang berarti binatang sembelihan, seperti unta, sapi atau kerbau, dan kambing yang disembelih pada hari raya Idul Adha dan harihari tasyriq sebagai bentuk taqarrub atau mendekatkan diri kepada Allah [2].
Pada dasarnya hewan yang di Qurbankan memiliki kriteria tertentu apakah hewan tersebut layak untuk di Qurbankan atau tidak. Oleh karena itu dilakukan pengecekkan terlebih dahulu kepada hewan tersebut apakah sesuai kriteria atau tidak. Kriteria tersebut meliputi umur hewan, bobot hewan, kecacatan hewan, jenis kelamin, dan warna hewan [3][4].

Diantara kriteria tersebut ada yang bersifat mutlak seperti umur, bobot, dan kecacatan hewan. Dimana ketika ketiga syarat tersebut tidak terpenuhi mengakibatkan hewan tersebut tidak sah menjadi hewan Qurban. Oleh karena itu dibutuhkan pengecekkan secara teliti untuk menentukan kualitas dari hewan Qurban tersebut. Tingginya angka jumlah Qurban di Indonesia menjadi tantangan apabila ingin melakukan pengecekkan kualitas hewan Qurban secara manual. Oleh karena itu diperlukan sebuah sistem pendukung keputusan yang dapat 
secara otomatis melakukan pengecekkan kualitas hewan Qurban.

Sistem pendukung keputusan (SPK) adalah sistem yang mampu memberikan kemampuan pemecahan masalah maupun kemampuan pengkomunikasian untuk masalah dengan kondisi semi terstruktur dan tak terstruktur. Sistem ini digunakan untuk membantu pengambilan keputusan dalam situasi semi terstruktur dan situasi yang tidak terstruktur, di mana tak seorang pun tahu secara pasti bagaimana keputusan seharusnya dibuat [5]. Sistem ini hanya merupakan pendukung dari pengambilan sebuah keputusan karena keputusan sepenuhnya berada pada pemilik keputusan.

Sistem pendukung keputusan ini sebagai penentu kualitas dari hewan Qurban dimana panitia Qurban dalam hal ini sebagai Decision Maker. Sistem ini menggunakan metode Simple Additive Weighting (SAW) yang dikenal sebagai metode penjumlahan berbobot. Konsep dasar dari metode SAW adalah mencari penjumlahan terbobot dari kinerja setiap alternatif pada semua atribut [6].

Simple Addictive Weighting (SAW) merupakan salah satu bagian dari metode MADM (Multi Attribute Decision Making) yang paling sederhana dan banyak digunakan. Hal ini dikarenakan metode ini mudah untuk diaplikasikan dan tidak memiliki algoritma yang sulit [7]. Sehingga metode SAW menjadi pilihan untuk digunakan dalam perancangan sistem keputusan untuk menentukan kualitas hewan Qurban.
Sistem pendukung keputusan ini dirancang untuk menyempurnakan penelitian sebelumnya yang dilakukan oleh Dedy Mulyanto,dkk dengan judul "Sistem Pakar Kelayakan Hewan Qurban Secara Syariah dan Kesehatan Berbasis Web. Pada penelitian ini, sistem yang dikembangkan berupa sistem pakar yang dimana atribut dari hewan hanya berfokus pada umur dan kecacatan [8]. Oleh sebab itu, diperlukan penambahan atribut dan metode perhitungan agar dapat mengklasifikasikan tingkat kelayakan dari hewan Qurban secara lebih baik.

Pada sistem penentu kualitas hewan Qurban yang dikembangkan menggunakan beberapa kriteria yang telah didapat berdasarkan studi literatur yang telah dilakukan. Kriteria tersebut disusun berdasarkan tingkat urgensinya yang berpengaruh sah atau tidaknya hewan Qurban. Tingkat urgensi tersebut diimplementasikan dalam bentuk nilai kriteria.

Tujuan penelitian ini adalah membuat desain sistem pendukung keputusan penentuan kualitas hewan Qurban dengan menerapkan metode Simple Additive Weighting (SAW). Dengan harapan, tulisan ini dapat membantu memberikan gambaran tentang sistem yang akan di implementasikan untuk menentukan kualitas hewan Qurban di Indonesia.

\section{METODE}

Metode yang digunakan dapat digambarkan dengan diagram alir pada gambar 1.

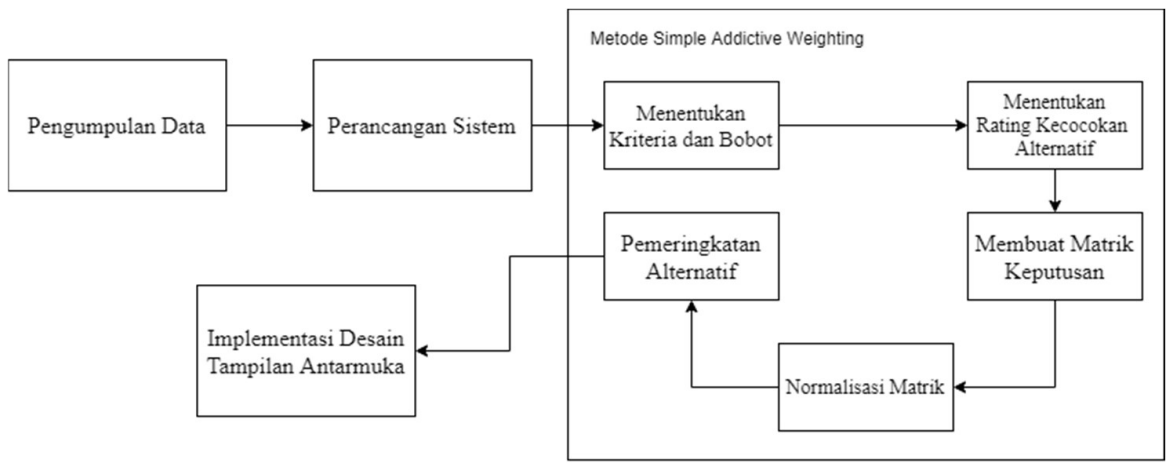

Gambar 1. Metode Pelaksanaan

Penelitian ini menggunakan data sekunder yang berasal dari beberapa sumber data literatur seperti jurnal, skripsi, website terpercaya dan artikel. Sumber data tersebut dianalisis untuk menemukan solusi atas permasalahan yang akan dipecahkan. Selanjutnya hasil dari analisis tersebut akan di implementasikan dalam bentuk perancangan sistem penentuan kualitas hewan Qurban. Perancangan sistem menjelaskan tentang bagaimana rancangan sistem penentuan kualitas hewan Qurban dengan menggunakan metode SAW. Adapun gambaran dari sistem dapat dilihat pada Usecase Diagram di gambar 2.

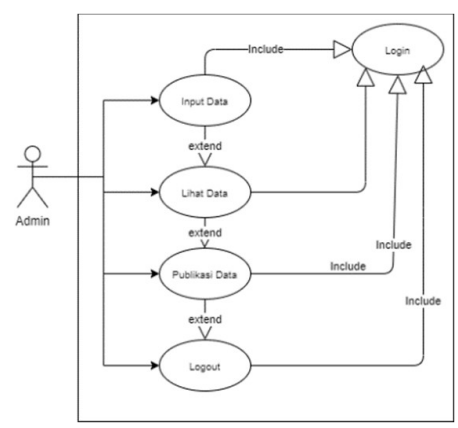

Gambar 2. Usecase Diagram

Usecase Diagram merupakan diagram yang bekerja dengan cara mendeskripsikan tipikal interaksi antara user (pengguna) sebuah sistem dengan suatu sistem tersendiri melalui sebuah alur cerita 
bagaimana sebuah sistem dipakai. Use case diagram terdiri dari sebuah aktor dan interaksi yang dilakukannya, aktor tersebut dapat berupa manusia, perangkat keras, sistem lain, ataupun yang berinteraksi dengan sistem [9].

Usecase diagram pada sistem penentuan kualitas hewan Qurban memiliki 1 pengguna yaitu admin. Admin merupakan orang yang akan mengoperasikan sistem mulai dari input data, proses data hingga mengambil data hasil proses.

Secara umum, admin didalam sistem dapat melakukan login untuk dapat mengakses sistem, yang dimana membutuhkan username dan password. Setelah memasukkan username dan password, admin dapat melakukan 3 hal didalam sistem, yang pertama adalah melakukan input data hewan Qurban dengan memasukkan hewan yang memiliki kriteria-kriteria tertentu, yang kemudian data tersebut akan diproses oleh sistem dan ditampilkan dalam bentuk tabel. Admin dapat memilih untuk melakukan publikasi data dengan fitur publikasi.

Metode perhitungan yang digunakan dalam kepenulisan ini adalah metode Simple Additive Weighting (SAW). Metode Simple Additive Weighting (SAW) dikenal juga dengan istilah metode penjumlahan terbobot. Konsep dasar metode SAW adalah mencari penjumlahan terbobot dari rating kinerja pada setiap alternatif pada semua atribut. Metode SAW membutuhkan proses normalisasi matriks keputusan (X) ke suatu skala yang dapat diperbandingkan dengan semua rating alternatif yang ada. Metode ini merupakan metode yang paling terkenal dan paling banyak digunakan dalam menghadapi situasi Multiple Attribute Decision Making (MADM) [10].

Simple Addictive Weighting termasuk dalam metode MADM. MADM merupakan metode yang digunakan untuk mencari alternatif optimal dari sejumlah alternatif dengan menggunakan kriteria tertentu [11]. Metode Simple Addictive Weighting termasuk dalam metode MADM. Dari MADM akan dilakukan penyeleksian dengan menggunakan Simple Additive Weighting (SAW) yaitu mencari penjumlahan terbobot dan rating kinerja pada setiap alternatif pada semua atribut yang ada [12].

Ada beberapa langkah dalam penyelesaian metode Simple Additive Weighting (SAW) adalah sebagai

berikut:

a. Menentukan kriteria-kriteria yang dijadikan acuan dalam pendukung keputusan yaitu $\mathrm{Ci}$.

b. Memberikan nilai bobot untuk masing-masing kriteria sebagai $\mathrm{W}$.

c. Menentukan rating kecocokan setiap alternatif pada setiap kriteria.

d. Membuat matriks keputusan berdasarkan kriteria (Ci).

e. Kemudian melakukan normalisasi matriks berdasarkan persamaan yang disesuaikan dengan jenis atribut (atribut keuntungan maupun atribut biaya) sehingga diperoleh matriks ternormalisasi $\mathrm{r}$.

f. Hasil akhir diperoleh dari proses perangkingan yaitu penjumlahan dari perkalian matriks ternormalisasi $r$ dengan vector bobot sehingga diperoleh nilai terbesar yang dipilih sebagai alternatif terbaik (Ai) sebagai solusi[13].
Berikut rumus yang diperlukan dalam menggunakan metode SAW:

$$
r_{i j}= \begin{cases}\frac{X_{i j}}{\operatorname{Max}_{i j}} \rightarrow & \text { Jika } j \text { adalah attribute keuntungan } \\ \text { (benefit) }\end{cases}
$$

Keterangan :

$$
\begin{aligned}
& \mathrm{rij}=\text { Rating kinerja ternormalisasi } \\
& \mathrm{Max}=\text { Nilai maksimum dari setiap baris dan kolom } \\
& \mathrm{Min}=\text { Nilai minimum dari setiap baris dan kolom } \\
& \mathrm{Xij}=\text { Baris dan kolom dari matriks }
\end{aligned}
$$

Dengan rij adalah rating kinerja ternormalisasi dari alternatif $\mathrm{Ai}$ pada atribut $\mathrm{Cj} ; \mathrm{i}=1,2, \ldots \mathrm{m}$ dan $\mathrm{j}=1,2, \ldots, \mathrm{n}$. Dalam menentukan bobot dari setiap atribut diperlukan matrik keputusan yang digambarkan sebagai berikut :

$$
\mathrm{R}=\left[\begin{array}{lll}
X i j & X i j & X i j \\
X i j & X i j & X i j \\
X i j & X i j & X i j
\end{array}\right]
$$

Tahap akhir dari perhitungan metode SAW adalah dengan melakukan pemeringkatan dari setiap alternatif dengan rumus sebagai berikut :

$$
\mathrm{V}_{\mathrm{i}}=\sum_{\mathrm{j}=1}^{\mathrm{n}} \mathrm{w}_{\mathrm{j}} \mathrm{r}_{\mathrm{ij}}
$$

Keterangan :

$\mathrm{Vi}=$ Nilai akhir dari alternatif

$\mathrm{wj}=$ Bobot yang telah ditentukan

rij $=$ Normalisasi matriks

Nilai yang lebih besar menandakan bahwa alternatif semakin lebih baik untuk dipilih [14].

\section{HASIL}

\subsection{Desain Tampilan Antarmuka}

Tampilan antarmuka dari sistem penentuan kualitas hewan Qurban memiliki 4 desain utama, yaitu sebagai berikut :

\subsubsection{Tampilan Login Sistem}
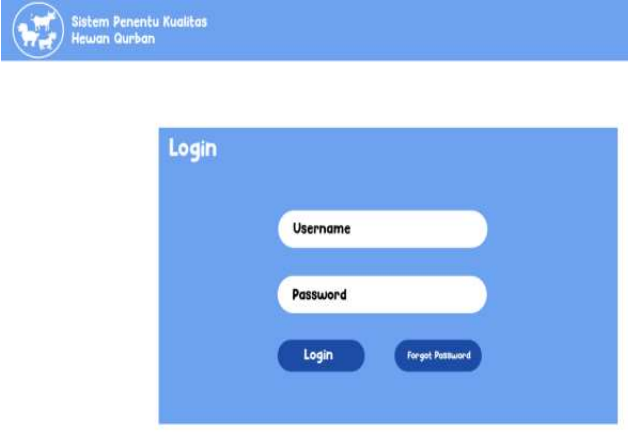

Gambar 3. Tampilan Login 
Tampilan Login sistem merupakan tampilan awal yang akan dilihat oleh pengguna apabila ingin melakukan pengaksesan terhadap sistem seperti yang terlihat pada Gambar 3. Agar dapat melakukan akses, pengguna diminta untuk memasukkan Username dan Password. Apabila username dan password sesuai maka pengguna dapat melakukan akses sistem. Namun, apabila username dan password tidak sesuai, maka pengguna tidak akan dapat mengakses sistem. Username dan Password dibuat oleh instansi terkait yang ditujukan oleh orang-orang tertentu yang dalam hal ini adalah pengelola hewan Qurban.

\subsubsection{Tampilan Beranda Sistem}

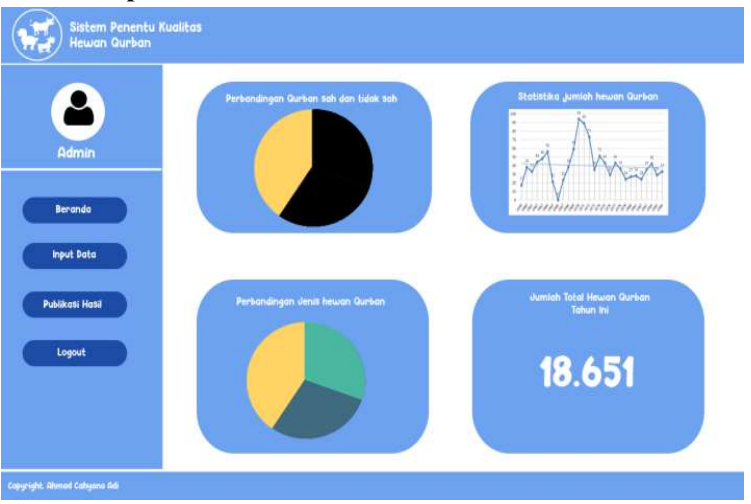

Gambar 4. Tampilan Beranda

Gambar 4 merupakan tampilan awal apabila pengguna berhasil memasukkan username dan password yang sesuai. Pada tampilan beranda terdapat sidebar yang mengandung profil admin dan beberapa tombol navigasi untuk dapat mengakses fitur lain. Pada tombol navigasi, terdapat tombol beranda, input data, publikasi hasil dan logout. Pada tampilan main, terdapat 4 kontainer yang mengandung statistika data-data tertentu. Kontainer tersebut meliputi data perbandingan jenis hewan Qurban yang ada di Indonesia pada tahun tertentu, data perbandingan hewan Qurban sah dan yang tidak sah, data tentang grafik jumlah hewan Qurban dari tahun ke tahun, dan yang terakhir adalah data terkait jumlah hewan Qurban pada tahun tertentu.

\subsubsection{Tampilan Input Data Sistem}

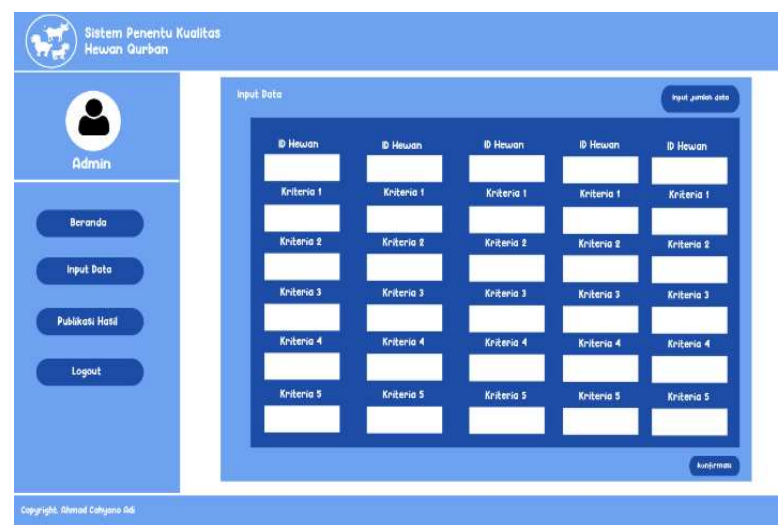

Gambar 5. Tampilan Input Data

Gambar 5 data sistem merupakan tampilan yang berfungsi untuk melakukan input data dari hewan Qurban. Pada tampilan main, terdapat pada pojok kanan atas sebuah tombol input jumlah data yang berfungsi agar pengguna dapat menginputkan data sesuai https://doi.org/10.25077/TEKNOSI.v7i2.2021.44-51 dengan jumlah yang di inginkan. Ketika pengguna mengetikkan angka tertentu, maka sistem akan memberikan tabel sebanyak jumlah yang di masukkan oleh pengguna. Setelah itu pengguna dapat melakukan input ID hewan, kriteria 1 hingga kriteria 5. Setelah berhasil melakukan input pada semua data, maka pengguna dapat menekan tombol konfirmasi untuk memberikan data kepada sistem agar dapat diproses dan mendapatkan hasilnya.

\subsubsection{Tampilan Publikasi Hasil}

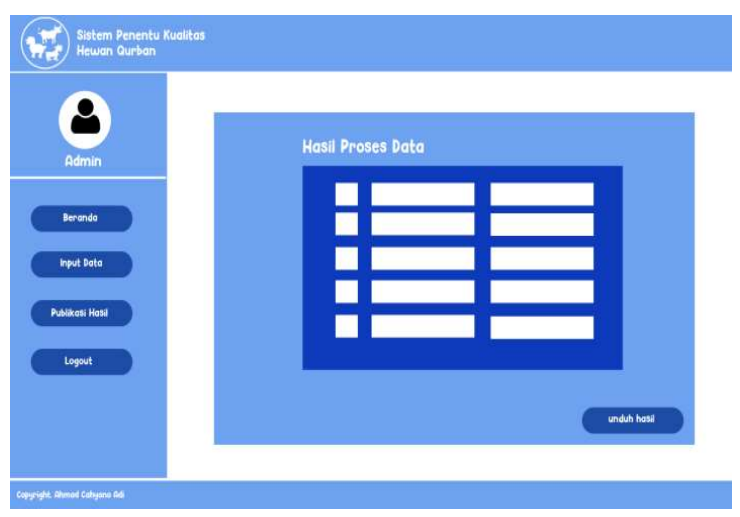

Gambar 6. Tampilan Input Data

Gambar 6 merupakan tampilan ketika data sudah berhasil diproses, data yang telah diproses ditampilkan dalam bentuk tabel dan dilakukan perankingan mulai dari nilai yang paling besar hingga nilai yang paling kecil. Pada tabel juga diberikan keterangan yang menandakan apakah hewan tersebut memenuhi syarat atau tidak.

\section{PEMBAHASAN}

\subsection{Penentuan Kriteria}

Dalam perancangan sistem pendukung keputusan, kriteria merupakan salah satu hal yang paling utama dalam memecahkan masalah.

Tabel 1. Kriteria Umur

\begin{tabular}{|c|c|c|c|}
\hline Hewan & Kriteria & $\begin{array}{c}\text { Sub- } \\
\text { kriteria }\end{array}$ & $\begin{array}{c}\text { Nilai } \\
\text { Kriteria }\end{array}$ \\
\hline \multirow[t]{3}{*}{ Sapi } & Umur & $<2$ tahun & 0.01 \\
\hline & & $\begin{aligned}> & =2 \text { tahun }< \\
& =3 \text { tahun }\end{aligned}$ & 1 \\
\hline & & $>3$ tahun & 0.3 \\
\hline \multirow[t]{4}{*}{ Kambing } & Umur & $<1$ tahun & 0.01 \\
\hline & & $>=1$ tahun & 1 \\
\hline & & $<=2$ tahun & \\
\hline & & $>2$ tahun & 0.3 \\
\hline \multirow[t]{4}{*}{ Domba } & Umur & $<6$ bulan & 0.01 \\
\hline & & $>=6$ bulan & 1 \\
\hline & & $\begin{array}{c}<=1 \text { tahun } 6 \\
\text { bulan }\end{array}$ & \\
\hline & & $\begin{array}{c}>1 \text { tahun } 6 \\
\text { bulan }\end{array}$ & 0.3 \\
\hline
\end{tabular}


Tabel 1 merupakan kriteria yang memiliki tingkat urgen paling tinggi, sebab apabila umur tidak memenuhi dari syarat maka hewan Qurban dikatakan tidak sah. Umur dari tiap-tiap hewan Qurban bervariasi tergantung dari jenis hewan Qurbannya.

Tabel 2. Kriteria Berat Hewan

\begin{tabular}{cccc}
\hline Hewan & Kriteria & $\begin{array}{c}\text { Sub- } \\
\text { kriteria }\end{array}$ & $\begin{array}{c}\text { Nilai } \\
\text { Kriteria }\end{array}$ \\
\hline Sapi & Bobot & $<200 \mathrm{Kg}$ & 0.2 \\
& & $200 \mathrm{~kg}-300$ & 0.7 \\
& & $\mathrm{~kg}$ & \\
& & $300 \mathrm{~kg}$ & 1 \\
Domba & Bobot & $<23 \mathrm{~kg}$ & 0.2 \\
dan & & $23 \mathrm{Kg}-28 \mathrm{Kg}$ & 0.7 \\
kambing & & & \\
& & $>28 \mathrm{Kg}$ & 1 \\
\hline
\end{tabular}

Tabel 2 merupakan kriteria dengan tingkat urgensi kedua setelah kriteria umur, hal ini dikarenakan bobot atau berat dari hewan mempengaruhi apakah hewan tersebut sah untuk di Qurbankan atau tidak. Oleh karena itu, klasifikasi dari bobot hewan Qurban diperlukan untuk menentukan nilai kriteria dari kriteria berat hewan. Berat dari tiap-tiap hewan berbeda tergantung dari jenis hewan Qurban. Semakin berat hewan Qurban maka semakin baik nilainya.

Tabel 3. Kriteria Kecacatan Hewan

\begin{tabular}{cccc}
\hline Hewan & Kriteria & $\begin{array}{c}\text { Sub- } \\
\text { kriteria }\end{array}$ & $\begin{array}{c}\text { Nilai } \\
\text { Kriteria }\end{array}$ \\
\hline $\begin{array}{c}\text { Sapi, } \\
\text { kambing, } \\
\text { domba }\end{array}$ & Kecacatan & Cacat & 0.01 \\
& & Tidak Cacat & 1
\end{tabular}

Tabel 3 merupakan kriteria dengan tingkatan urgensi ketiga. Hal ini dikarenakan kecacatan pada hewan Qurban dapat menjadikan hewan Qurban tersebut tidak sah untuk di Qurbankan. Terdapat kecacatan tertentu yang dapat mengkategorikan hewan Qurban tergolong cacat atau tidak.

Tabel 4. Kriteria Warna Hewan

\begin{tabular}{cccc}
\hline Hewan & Kriteria & $\begin{array}{c}\text { Sub- } \\
\text { kriteria }\end{array}$ & $\begin{array}{c}\text { Nilai } \\
\text { Kriteria }\end{array}$ \\
\hline Sapi, & Warna & Putih Polos & 1 \\
kambing, & Hewan & & \\
domba & & Abu Abu & 0.75 \\
& & Hitam & 0.5 \\
& & Warna Lain & 0.25 \\
\hline
\end{tabular}

Tabel 4 merupakan kriteria tambahan yang dapat membuat hewan Qurban semakin berkualitas. Berdasarkan literatur yang telah didapat, hewan Qurban yang memiliki warna putih lebih diutamakan untuk di Qurbankan dibanding dengan warna lain. Meski demikian kriteria ini tidak berpotensi membuat hewan Qurban menjadi tidak sah, hanya saja menambah nilai dari hewan Qurban menjadi semakin baik.
Tabel 5. Kriteria Jenis Kelamin

\begin{tabular}{cccc}
\hline Hewan & Kriteria & $\begin{array}{c}\text { Sub- } \\
\text { kriteria }\end{array}$ & $\begin{array}{c}\text { Nilai } \\
\text { Kriteria }\end{array}$ \\
\hline $\begin{array}{c}\text { Sapi, } \\
\text { kambing, } \\
\text { domba }\end{array}$ & $\begin{array}{c}\text { Jenis } \\
\text { Kelamin }\end{array}$ & Jantan & 1 \\
& & Betina & 0.5 \\
\hline
\end{tabular}

Tabel 5 merupakan kriteria tambahan kedua yang didapat pada literatur. Hewan Qurban yang di Qurbankan berdasarkan literatur yang didapat adalah diutamakan melakukan Qurban dengan hewan berjenis kelamin jantan. Namun kriteria ini tidak menjadikan hewan Qurban menjadi tidak sah, hanya saja sebagai nilai tambah terhadap hewan Qurban tersebut yang dapat meningkatkan kualitas dari hewan Qurban.

\subsection{Penentuan Jenis dan Bobot Kriteria}

Bobot merupakan sebuah bilangan yang ditetapkan pada setiap butir soal atau pertanyaan yang nilainya ditentukan berdasarkan usaha atau testi. Sedangkan nilai adalah hasil pengolahan atau skor yang diolah menggunakan metode atau aturan tertentu sehingga dapat diinterpretasikan [15].

Jenis kriteria dan Bobot Kriteria ditentukan untuk memudahkan seseorang dalam melakukan perhitungan terhadap kriteria yang ada. Jenis kriteria digunakan untuk menentukan apakah kriteria termasuk kedalam "cost" atau "benefit". Cost adalah semakin kecil maka nilai semakin besar, sedangkanbenefit adalah semakin besar maka semakin besar.

Tabel 6. Jenis Kriteria dan Bobot

\begin{tabular}{ccc}
\hline Kriteria & Jenis Kriteria & Bobot Kriteria \\
\hline Umur & Benefit & $40 \%$ \\
Berat Hewan & Benefit & $20 \%$ \\
Kecacatan & Benefit & $25 \%$ \\
Warna Hewan & Benefit & $10 \%$ \\
Jenis Kelamin & Cost & $5 \%$ \\
\hline
\end{tabular}

Tabel 6 adalah penentuan bobot kriteria ditentukan berdasarkan tingkat urgensi dari tiap tiap kriteria. Kriteria dengan tingkat urgensi yang tinggi akan mendapatkan bobot yang lebih besar, hal ini dikarenakan apabila dilakukan perhitungan maka bobot dari kriteria tersebut dapat mendominasi sehingga hasil yang didapatkan sesuai dengan prediksi. Semakin kecil tingkat urgensi dari kriteria maka bobot yang diberikan juga semakin kecil.

Pada tabel diatas, bobot kriteria menggunakan sistem persentase dengan range $0 \%-100 \%$, dimana pada simulasi perhitungan maka nilai tersebut akan dikonversikan sebagai nilai pecahan agar memudahkan proses perhitungan dan mendapatkan nilai dari tiap-tiap kriteria.

\subsection{Perhitungan Penentuan Kualitas Hewan Qurban}

Terdapat sebuah data dengan kriteria tertentu dengan tujuan untuk menguji ketepatan hasil perhitungan dengan menggunakan metode SAW. Data tersebut dapat dilihat pada Tabel 7. 
Tabel 7. Data Simulasi Hewan

\begin{tabular}{llllll}
\hline \multirow{2}{*}{ Alternatif } & \multicolumn{5}{c}{ Kriteria } \\
\cline { 2 - 6 } & $\begin{array}{l}\text { Umur } \\
(\mathrm{C} 1)\end{array}$ & $\begin{array}{c}\text { Berat } \\
(\mathrm{C} 2)\end{array}$ & $\begin{array}{c}\text { Kecacatan } \\
(\mathrm{C} 3)\end{array}$ & $\begin{array}{c}\text { Warna } \\
\text { hewan } \\
(\mathrm{C} 4)\end{array}$ & $\begin{array}{c}\text { Jenis } \\
\text { Kelamin } \\
(\mathrm{C} 5)\end{array}$ \\
\hline sapi & 2 & 300 & tidak & putih & jantan \\
& tahun & $\mathrm{kg}$ & & & \\
\hline sapi & 4 & 350 & cacat & coklat & jantan \\
& tahun & $\mathrm{kg}$ & & & \\
\hline kerbau & 1 & 150 & cacat & putih & jantan \\
& tahun & $\mathrm{kg}$ & & & \\
\hline kambing & 2 & 25 & tidak & hitam & betina \\
& tahun & $\mathrm{kg}$ & & & \\
\hline domba & 1 & 30 & tidak & putih & betina \\
& tahun & $\mathrm{kg}$ & & & \\
\hline
\end{tabular}

Selanjutnya data tersebut akan dilakukan normalisasi untuk menentukan nilai kriteria pada setiap alternatif. Setiap kriteria pada alternatif akan diberi nilai sesuai dengan tingkatan nilai kriteria yang sudah ditentukan sehingga didapat hasilnya sebagai berikut.

Tabel 8. Nilai Kriteria Tiap Alternatif

\begin{tabular}{cccccc}
\hline \multirow{2}{*}{ Alternatif } & \multicolumn{5}{c}{ Kriteria } \\
\cline { 2 - 6 } & $\begin{array}{c}\text { Umur } \\
(\mathrm{C} 1)\end{array}$ & $\begin{array}{c}\text { Berat } \\
(\mathrm{C} 2)\end{array}$ & $\begin{array}{c}\text { Kecacatan } \\
(\mathrm{C} 3)\end{array}$ & $\begin{array}{c}\text { Warna } \\
\text { hewan } \\
(\mathrm{C} 4)\end{array}$ & $\begin{array}{c}\text { Jenis } \\
\text { Kelamin } \\
(\mathrm{C} 5)\end{array}$ \\
\hline sapi & 1 & 1 & 1 & 1 & 1 \\
\hline sapi & 0.3 & 1 & 0.01 & 0.25 & 1 \\
\hline kerbau & 0.01 & 0.2 & 0.01 & 1 & 1 \\
\hline kambing & 1 & 0,7 & 1 & 0.5 & 0.5 \\
\hline domba & 1 & 1 & 1 & 1 & 0.5
\end{tabular}

Data alternatif yang sudah memiliki nilai kriteria selanjutnya akan dibuat matrik keputusan untuk dilakukan proses perhitungan.

$\mathrm{R}=\left[\begin{array}{ccccc}1 & 1 & 1 & 1 & 1 \\ 0.3 & 1 & 0.01 & 0.25 & 1 \\ 0.01 & 0.2 & 0.01 & 1 & 1 \\ 1 & 0.7 & 1 & 0.5 & 0.5 \\ 1 & 1 & 1 & 1 & 0.5\end{array}\right]$

Data yang terdapat didalam matrik selanjutnya akan dilakukan normalisasi dari setiap kriteria dengan menggunakan rumus sebagai berikut.

$\mathrm{R}_{\mathrm{ij}}=\left\{\begin{array}{c}\frac{x i j}{\text { MaxXiXi }} \text { Jika } j \text { adalah atribut keuntungan (Benefit) } \\ \frac{\text { Min } i \text { Xij }}{X i j} \quad \text { Jika } j \text { adalah atribut biaya }(\text { Cost })\end{array}\right.$

Kriteria umur (Benefit)

$$
\begin{aligned}
\mathrm{R} 11 & =\frac{1}{\operatorname{Max}(1,0.3,0.01,1,1)}=1 \quad \mathrm{R} 12=\frac{1}{\operatorname{Max}(1,0.3,0.01,1,1) j}=1 \\
\mathrm{R} 13 & =\frac{1}{\operatorname{Max}(1,0.3,0.01,1,1) j}=1 \\
\mathrm{R} 14 & =\frac{1}{\operatorname{Max}(1,0.3,0.01,1,1) j}=1 \quad \mathrm{R} 15=\frac{1}{\operatorname{Max}(1,0.3,0.01,1,1) j}=1
\end{aligned}
$$

Kriteria Berat Hewan (Benefit)

$$
\begin{aligned}
& \mathrm{R} 21=\frac{0.3}{\operatorname{Max}(1,1,0.2,0.7,1)}=0.3 \quad \mathrm{R} 22=\frac{1}{\operatorname{Max}(1,1,0.2,0.7,1)}=1 \\
& \mathrm{R} 23=\frac{0.01}{\operatorname{Max}(1,1,0.2,0.7,1)}=0.01 \\
& \mathrm{R} 24=\frac{1}{\operatorname{Max}(1,1,0.2,0.7,1) j}=1 \quad \mathrm{R} 25=\frac{1}{\operatorname{Max}(1,1,0.2,0.7,1) j}=1
\end{aligned}
$$

Kriteria Kecacatan (Benefit)

$$
\begin{aligned}
& \mathrm{R} 31=\frac{0.01}{\operatorname{Max}(1,0.01,0.01,1,1)}=0.01 \\
& \mathrm{R} 32=\frac{0.2}{\operatorname{Max}(1,1,0.2,0.7,1)}=0.02 \\
& \mathrm{R} 33=\frac{0.01}{\operatorname{Max}(1,1,0.2,0.7,1)}=0.01 \\
& \mathrm{R} 34=\frac{1}{\operatorname{Max}(1,1,0.2,0.7,1)}=1 \\
& \mathrm{R} 35=\frac{1}{\operatorname{Max}(1,1,0.2,0.7,1)}=1
\end{aligned}
$$

Kriteria Warna Hewan (Benefit)

$$
\begin{aligned}
& \mathrm{R} 41=\frac{1}{\operatorname{Max}(1,1,0.2,0.7,1)}=1 \quad \mathrm{R} 42=\frac{0.7}{\operatorname{Max}(1,1,0.2,0.7,1)}=0.7 \\
& \mathrm{R} 43=\frac{1}{\operatorname{Max}(1,1,0.2,0.7,1)}=1 \quad \mathrm{R} 44=\frac{0.5}{\operatorname{Max}(1,1,0.2,0.7,1)}=0.5 \\
& \mathrm{R} 45=\frac{0.5}{\operatorname{Max}(1,1,0.2,0.7,1)}=0.5
\end{aligned}
$$

Kriteria Jenis Kelamin (Cost)

$\mathrm{R} 51=\frac{\operatorname{Min}(1,0.25,1,0.5,1)}{1}=0.25$

$\mathrm{R} 52=\frac{\operatorname{Min}(1,0.25,1,0.5,1)}{1}=0.25$

$\mathrm{R} 53=\frac{\operatorname{Min}(1,0.25,1,0.5,1)}{1}=0.25$

$\mathrm{R} 54=\frac{\operatorname{Min}(1,0.25,1,0.5,1)}{1}=0.25$

$\mathrm{R} 55=\frac{\operatorname{Min}(1,0.25,1,0.5,1)}{0.5}=0.5$

$\mathrm{R}=\left[\begin{array}{ccccc}1 & 1 & 1 & 1 & 1 \\ 0.3 & 1 & 0.01 & 0.25 & 1 \\ 0.01 & 0.2 & 0.01 & 1 & 1 \\ 1 & 0.7 & 1 & 0.5 & 0.5 \\ 1 & 1 & 1 & 1 & 0.5\end{array}\right]$

Hasil tersebut akan dilakukan operasi untuk mendapakan nilai ranking dari setiap alternatif yang tersedia dengan perhitungan sebagai berikut. Nilai yang didapat setelah normalisasi adalah sebagai berikut

$\mathrm{V} 11=(1)(0.4)+(1)(0.2)+(0.01)(0.25)+(1)(0.1)+(0.25)(0.05)=$ 0.715

$\mathrm{V} 12=(1)(0.4)+(1)(0.2)+(0.02)(0.25)+(0.5)(0.1)+(0.25)(0.05)$ $=0.6675$

$\mathrm{V} 13=(1)(0.4)+(0.01)(0.2)+(0.02)(0.25)+(1)(0.1)+(0.25)(0.05)$

$=0.5195$

$\mathrm{V} 14=(1)(0.4)+(1)(0.2)+(1)(0.25)+(1)(0.1)+(0.25)(0.05)$ $=0.9625$

$\mathrm{V} 15=(1)(0.4)+(1)(0.2)+(1)(0.25)+(0.5)(0.1)+(0.5)(0.05)$ $=0.925$ 
Tabel 9. Nilai Hasil Perhitungan

\begin{tabular}{l|c}
\hline \multicolumn{1}{c|}{ Hewan } & Nilai \\
\hline Sapi & 0.715 \\
\hline Sapi & 0.66 \\
\hline Kerbau & 0.5195 \\
\hline Kambing & 0.9625 \\
\hline Domba & 0.925 \\
\hline
\end{tabular}

Berdasarkan nilai yang didapat seperti terlihat pada tabel 9, maka akan diklasifikasikan berdasarkan tabel nilai kriteria berikut yang akan memberikan predikat pada setiap alternatif termasuk dalam predikat apa nantinya.
Tabel 10. Predikat Tiap Range Nilai

\begin{tabular}{ll}
\hline Range Nilai & Predikat \\
\hline$<0.7$ & Tidak sah \\
\hline$>0,7-0,89$ & Sah \\
\hline$>=0.90$ & Sah dan sangat baik \\
\hline
\end{tabular}

Sehingga dari tabel predikat diatas, maka hasil nilai dari setiap alternatif hewan akan dicocokkan dengan rentang nilai yang terdapat pada tabel 10 .

\subsection{Analisis Hasil Perhitungan}

Berdasarkan simulasi hasil perhitungan diatas, maka didapat hasil akhir berupa ranking dan keputusan akhir apakah hewan Qurban termasuk dalam kategori layak atau tidak untuk di Qurbankan. Tabel 11 adalah hasil akhir dari perhitungan.

Tabel 11. Hasil Akhir Perhitungan

\begin{tabular}{cccc}
\hline Ranking & Hewan & Nilai & Predikat \\
\hline 1 & Kambing & 0.9625 & $\begin{array}{c}\text { Sah dan } \\
\text { sangat baik }\end{array}$ \\
\hline 2 & Domba & 0.925 & $\begin{array}{c}\text { Sah dan } \\
\text { sangat baik }\end{array}$ \\
\hline 3 & Sapi & 0.715 & Sah \\
\hline 4 & Sapi & 0.66 & Tidak sah \\
\hline 5 & Kerbau & 0.5195 & Tidak sah \\
\hline
\end{tabular}

Berdasarkan tabel 11 didapat bahwa hasil dari proses perankingan menunjukkan bahwa akurasi dari sistem menggunakan metode perhitungan SAW adalah $100 \%$ hal ini dibuktikan dengan dilakukan pengecekkan secara manual bahwa hewan dengan kriteria yang terdapat pada diatas sesuai dengan ketentuan fiqih Qurban yang berlaku.

Namun Metode SAW memiliki akurasi yang kurang, hal ini dikarenakan kriteria yang ditentukan harus dinamis dan memiliki cakupan yang luas [16]. Untuk mengatasi hal tersebut, kriteria yang dipilih harus merupakan kriteria yang mempengaruhi pemilihan alternatif sehingga ditentukan nilai mulai dari kriteria yang paling berpengaruh hingga kriteria yang memiliki pengaruh sedikit.

Metode SAW dapat melakukan penilaian secara lebih tepat, berdasarkan nilai kriteria dan bobot preferensi yang sudah ditentukan. Selain itu metode SAW mampu menyeleksi alternatif terbaik dari sejumlah alternatif yang ada [16]. Kelebihan dari Metode SAW dapat menentukan nilai bobot untuk setiap kriteria kemudian dilanjutkan dengan proses perankingan yang akan menyeleksi alternatif terbaik dari sejumlah alternatif. Hal ini menyebabkan penilaian akan dilakukan secara lebih cepat karena didasarkan pada nilai kriteria dari bobot yang telah ditentukan. [17]

\section{KESIMPULAN}

Sistem penentuan kualitas hewan Qurban merupakan sistem pendukung keputusan yang dirancang untuk membantu dalam memilih dan menentukan kualitas hewan Qurban yang ada di
Indonesia. Sistem ini menggunakan metode SAW yang terdapat dalam MADM. Dalam menentukan keputusan, sistem penentuan kualitas hewan Qurban memiliki 5 kriteria yang memiliki tingkat urgensi yang berbeda.

Simulasi perhitungan yang dilakukan mendapatkan hasil yang baik dengan persentase akurasi adalah $100 \%$ dengan jumlah 5 data uji. Untuk mendapatkan akurasi yang lebih baik, diperlukan pengujian dengan data yang lebih banyak sehingga hasil dari perhitungan sistem dapat dilihat akurasinya. Oleh sebab itu, diperlukan beberapa uji coba dan riset lebih lanjut agar sistem yang dirancang memiliki akurasi yang lebih baik sehingga dapat membantu dalam melakukan penentuan hewan Qurban apakah layak untuk di Qurbankan.

Kriteria yang diambil berdasarkan literatur yang terpercaya dimana kriteria tersebut merupakan kriteria yang mutlak dan dapat dipertanggunjawabkan. Namun untuk pengembangan sistem kedepannya, kriteria tersebut dapat ditambah agar kualitas hewan Qurban yang dihasilkan semakin baik. Dengan adanya sistem ini diharapkan dapat meningkatkan kualitas hewan Qurban yang ada di Indonesia.

\section{DAFTAR PUSTAKA}

[1] Aprianus Doni Dolok.'Kementan:Jumlah Hewan Kurban Turun 3,5 Persen Pada Tahun Ini." Internet :https://kabar24.bisnis.com/read/20200729/15/1272595/ke mentan-jumlah-hewan-kurban-turun-35-persen-pada-tahunini,29 Juli 2020 [4 Mei 2021]. 
[2] Mulyana Abdullah, 2016. Qurban : Wujud Kedekatan Hamba dengan Tuhannya. Jurnal Pendidikan Agama Islam Ta'lim, Vol 14 No 1 pp: 109-116.

[3] Muhammad Abduh Tuasikal.”Panduan Qurban.” Internet :https://rumaysho.com/2814-panduan-qurban.html, $\quad 18$ September 2012 [5 Mei 2021].

[4] Muhammad Abduh Tuasikal."Memilih Hewan Terbaik untuk Qurban.” Internet :https://rumaysho.com/3615memilih-hewan-terbaik-untuk-kurban.html, 10 September 2013 [5 Mei 2021].

[5] Turban E,Aronson EJ, Liang PT. Decision Support Systems and Intelligent Systems edisi 7 jilid 1. Yogyakarta: Andi. 2005. pp 100-102.

[6] Hermanto, Nailul Izzaj."Sistem Pendukung Keputusan Pemilihan Motor Dengan Metode Simple Additive Weighting (SAW)."Jurnal Matematika dan Pembelajaran Volume 6, No. 2, 184-200,2018

[7] Mulyati Sri, "Penerapan Metode Simple Additive Weighting Untuk Penentuan Prioritas Pemasaran Kemasan Produk Bakso Sapi”, Jurnal Informatika Universitas Pamulang 33 Vol.1, No.1,2016.

[8] Maryanto Dedy dkk, "Sistem Pakar Kelayakan Hewan Qurban Secara Syariah Dan Kesehatan Berbasis Web", Department of Informatics, Faculty of Communications and Informatics, Muhammadiyah university of Surakarta,2014.

[9] R. P. Pratama, I. Werdiningsih, and I. Puspitasari, "Sistem Pendukung Keputusan Pemilihan Siswa Berprestasi di Sekolah Menengah Pertama dengan Metode VIKOR dan TOPSIS,” J. Inf. Syst. Eng. Bus. Intell., vol. 3, no. 2, pp. 113-121,2017.

[10] Kurniawan Bayu. T,Syarifuddin, "Perancangan Sistem Aplikasi Pemesanan Makanan Dan Minuman Pada Cafetaria No Caffe Di Tanjung Balai Karimun Menggunakan Bahasa Pemograman PHP Dan Mysql”,Jurnal TIKAR Volume 1. No. 2, Teknik Informatika, Universitas Karimun,2020.

[11] Budiman, Arief dkk, "Sistem Pendukung Keputusan Dalam Pemilihan Pergururan Tinggi Terbaik Dengan Menggunakan Metode SAW (Simple Additive Weighting)", ALGORITMA: Jurnal Ilmu Komputer dan Informatika Volume: 04, Number: 01, April 2020 ISSN 2598-6341 (online), Universitas Harapan, Medan,2020.

[12] S.Suhada, dkk,'Penerapan Fuzzy Madm Model Weighted Product Dalam Pengambilan Keputusan Kelayakan Penerimaan Kredit Di BPR Nusamba Sukaraja",Jurnal JUITA, Vol.6, No.1,2018.

[13] Romadiana, Parlia, dkk,"Penerapan Metode Fuzzy Multi Attribut Decision Making (FMADM) dan Simple Addictive Weighting (SAW) untuk Penentuan Bujang Dayang Kota Pangkal Pinang”Jurnal Ilmu Komputer dan Teknologi Informasi Vol.5 No.2. ISB Atma Luhur Pangkalpinang, 2020.

[14] Pipyros, Kosmas., etc, "Cyber-Attacks Evaluation Using Simple Addictive Weighting On The Basic Of Schmitt's Analysis". in Tenth Mediterranean Conference on Information Systems (MCIS),2016,pp.8-10.

[15] Kusumadewi, Sri., Hartati, S., Harjoko, A., dan Wardoyo, R, Fuzzy Multi-Attribute Decision Making (FUZZY MADM),Yogyakarta: Penerbit Graha Ilmu,2006,78-79.

[16] A. Setiadi, Y. Yunita, and A. R. Ningsih, "Penerapan Metode Simple Additive Weighting(SAW) Untuk
Pemilihan Siswa Terbaik," J. Sisfokom (Sistem Inf. dan Komputer), vol. 7, no. 2, p. 104, 2018.

[17] Meriano Setya Dwi Utomo, "Penerapan Metode Saw (Simple Additive Weight) Pada Sistem Pendukung Keputusan Untuk Pemberian Beasiswa Pada Sma Negeri 1 Cepu Jawa Tengah",eprints Udinus Repository, Sistem Informasi Fakultas Ilmu Komputer Universitas Dian Nuswantoro, 2015.

\section{BIODATA PENULIS}

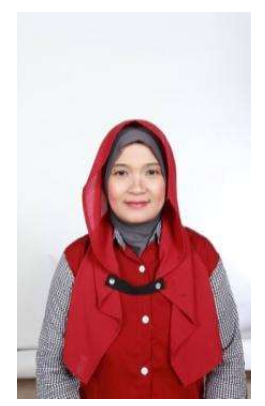

Penulis Pertama

Penulis bernama lengkap Renny Puspita Sari, S.T., M.T, tempat lahir di Kota Pontianak, Saat ini penulis merupakan dosen tetap jurusan di Sistem Informasi Fakultas Matematika dan Ilmu Pengetahuan Alam, Universitas Tanjungpura Pontianak.

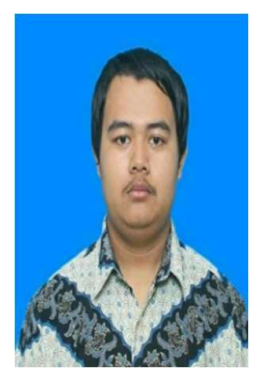

Penulis Kedua

Seorang mahasiswa semester 6 program studi sistem informasi FMIPA Universitas Tanjungpura yang bernama Ahmad Cahyono Adi. Lahir di Bengkayang, 28 Januari 2000. Berasal dari Bengkayang dan beralamat di jalan sepakat 2, Pontianak. 